\title{
Temperatura inicial de germinação no desempenho de plântulas e mudas de tomate
}

\author{
Germination temperature in tomato seedlings performance
}

\author{
Roberta Leopoldo Ferreira ${ }^{I^{*}}$ Victor Augusto Forti ${ }^{\mathrm{I}}$ Vanessa Neumann \\ Silva ${ }^{\text {II }}$ Simone da Costa Mello
}

\section{RESUMO}

A produção de mudas é uma das etapas fundamentais para o cultivo do tomateiro e pode ser influenciada pela temperatura inicial de germinação. Nesse sentido, o objetivo deste trabalho foi avaliar o efeito desse fator no desempenho de plântulas e mudas de tomate. Foram utilizados quatro lotes de sementes de tomate híbrido Mariana, submetidos aos testes de germinação, envelhecimento acelerado e condutividade elétrica para a avaliação do potencial fisiológico. Após a caracterização dos lotes, as sementes foram submetidas a diferentes temperaturas iniciais de germinação (20-30 alternada, 30, 33 e $35^{\circ} \mathrm{C}$ constantes) para determinação da curva de embebição e para análise de plântulas por meio do software SVIS ${ }^{\circledR}$. Sementes submetidas às mesmas temperaturas foram destinadas à produção de mudas e o desempenho destas foi avaliado por meio da velocidade e porcentagem de emergência, altura e massa seca da parte aérea e das raízes. As temperaturas mais elevadas prejudicam o desenvolvimento inicial das plântulas, porém as mudas submetidas às diferentes temperaturas, aos 28 dias após a semeadura, estavam com desempenho semelhante.

Palavras-chave: Solanum lycopersicun L., vigor, emergência de plântulas.

\section{ABSTRACT}

Seedling production is an important step for the tomato production and can be influenced by the initial temperature of germination. The aim of this study was to evaluate the effect of this factor in the tomato germination and seedling growth. It was used four seed lots which were tested for germination, accelerated aging and electrical conductivity to evaluate the physiological potential. After lots characterization, seeds were exposed to initial germination temperatures $\left(20-30,30,33\right.$ and $\left.35^{\circ} \mathrm{C}\right)$ and were analyzed by the SVIS ${ }^{\circledR}$ software. The seedling performance was evaluated using the emergence speed index and percentage, height and dry weight of shoots and roots. In general, the higher temperatures decreased the seedlings development. However, 28 days after sowing, the seedlings growth was similar among temperatures.

Key words: Solanum lycopersicun L., vigour, seedling emergence.

\section{INTRODUÇÃO}

A produção de mudas é uma das etapas fundamentais no processo de produção de tomate (Solanum lycopersicun L.), sendo importante para o desempenho das plantas no ambiente de cultivo (ANDRIOLO, 2002). Assim, mudas bem desenvolvidas, sadias e uniformes são menos suscetíveis aos estresses bióticos e abióticos e originam estandes mais homogêneos.

O processo de germinação de sementes envolve uma série de atividades metabólicas, durante as quais ocorre uma sequência de reações químicas, com exigências próprias quanto à temperatura, principalmente porque dela depende a atividade de sistemas enzimáticos específicos (MARCOS FILHO, 2005).

No início da germinação, a embebição resulta na hidratação das matrizes, como as células da parede celular (NONOGAKI et al., 2010; NONOGAKI, 2008), compostas por manose, glucose, galactose e arabinose em sementes de tomate. Para ocorrer a degradação dessas substâncias, é necessária a produção da enzima endo- $\beta$-mananase (MO \&

\footnotetext{
'Departamento de Produção Vegetal, Escola Superior de Agricultura "Luiz de Queiroz" (ESALQ), Universidade de São Paulo (USP), Av. Pádua Dias, 11, CP 9, 13418-900, Piracicaba, SP, Brasil. E-mail: robertalf@bol.com.br. *Autor para correspondência.

IInniversidade Federal do Pampa (UNIPAMPA), Campus Itaqui, Rua Luiz Joaquim Sá Britto, Itaqui, RS, Brasil.
} 
BEWLEY, 2003), cuja síntese de enzimas do tipo mananase parece ser reduzida pelo tratamento com altas temperaturas (SOZZI et al., 1996).

Assim, a temperatura é fundamental para a germinação, pois atua sobre a velocidade de absorção de água e nas reações bioquímicas que determinam todo o processo, de forma que, em consequência, afeta a velocidade, a uniformidade, bem como a germinação total, uma vez que esta ocorre dentro de determinados limites de temperatura, nos quais existe uma temperatura ótima para a obtenção da maior porcentagem de germinação em menor espaço de tempo (CARVALHO \& NAKAGAWA, 2000). Para sementes de tomate, foi recomendada a temperatura alternada, com ciclos de $20^{\circ} \mathrm{C}$ durante 16 horas e $30^{\circ} \mathrm{C}$ durante 8 horas (BRASIL, 2009), de forma que, quando a temperatura fica acima de $35^{\circ} \mathrm{C}$, a germinação das sementes e o crescimento de plântulas de tomate é afetado negativamente (WAHID et al., 2007).

Estudos com sementes de alface indicaram que temperaturas acima de $30^{\circ} \mathrm{C}$ reduziram a velocidade e/ou a porcentagem de germinação (NASCIMENTO \& CANTLIFFE, 2002); para sementes de rabanete, foi verificado que a máxima germinação ocorreu em temperaturas entre 10 e $20^{\circ} \mathrm{C}$, enquanto a temperatura de $35^{\circ} \mathrm{C}$ afetou negativamente a germinação (STEINER et al., 2009). Assim, dependendo do local e época de semeadura, a germinação das sementes pode ser reduzida ou nula, comprometendo o estande no campo ou em casa de vegetação.

Dessa forma, o objetivo neste trabalho foi avaliar o efeito da temperatura inicial de germinação no desempenho de plântulas e mudas de tomate.

\section{MATERIAL E MÉTODOS}

O trabalho foi conduzido no Laboratório de Sementes, Análise de Imagens e no Setor de Horticultura do Departamento de Produção Vegetal da Escola Superior de Agricultura "Luiz de Queiroz", em Piracicaba-SP, com quatro lotes de sementes condicionadas de tomate híbrido 'Mariana'. Inicialmente, avaliou-se o teor de água, a germinação (BRASIL, 2009) e o vigor por meio do teste de envelhecimento acelerado (JIANHUA \& MCDONALD, 1996) e condutividade elétrica (ISTA, 1995).

Após a determinação do potencial fisiológico, quatro repetições de 50 sementes previamente pesadas foram submetidas à determinação da curva de embebição, as quais foram distribuídas entre três folhas de papel toalha umedecidas com água, quantidade de água equivalente a 2,5 vezes a massa do substrato seco e colocadas em germinadores regulados às temperaturas de $20-30^{\circ} \mathrm{C}$ (testemunha), 30, 33 e $35^{\circ} \mathrm{C}$. As pesagens foram periódicas (intervalos de uma até 48 horas e, a partir deste ponto, em intervalos de duas horas), nas quais as sementes foram retiradas do papel toalha, secas superficialmente com papel de filtro, pesadas e colocadas novamente para embeber, cujo procedimento foi realizado até a protrusão da raiz primária de $10 \%$ das sementes.

Para avaliar o crescimento inicial das plântulas, utilizou-se a análise computadorizada de plântulas oriundas de quatro repetições de 25 sementes, as quais foram submetidas às temperaturas de $20-30^{\circ} \mathrm{C}$ (testemunha), 30,33 e $35^{\circ} \mathrm{C}$ por 48 horas, sendo posteriormente mantidas a $20-30^{\circ} \mathrm{C}$ por mais 48 horas para avaliação por meio do software Seed Vigor Image System ${ }^{\circledR}\left(\right.$ SVIS $\left.^{\circledR}\right)$. Para isso, as sementes foram colocadas sobre papel toalha umedecido com quantidade de água equivalente a 2,5 vezes a massa seca do papel, mantidas em germinador nas condições de temperatura descritas anteriormente. Em seguida, as imagens das plântulas foram obtidas por meio do uso de Scanner modelo HP Scanjet 2004, montado de maneira invertida e operado por software Photosmart com resolução de 100dpi (SILVA \& CICERO, 2011). Após a análise e a avaliação de cada plântula, o software SVIS ${ }^{\circledR}$ forneceu os valores para os índices de vigor (IV), crescimento (IC), uniformidade de crescimento de plântulas (IUC) e comprimento de plântula (CP). Os dados dos índices de vigor e uniformidade variam de 0 a 1000 e são diretamente proporcionais ao vigor da amostra de sementes, cujos valores foram baseados na rapidez e uniformidade de desenvolvimento das plântulas da amostra, que foram estabelecidos na programação do software (HOFFMASTER et al., 2003).

Para as avaliações de crescimento e desenvolvimento das mudas, quatro repetições de 50 sementes por tratamento foram semeadas em bandejas de polietileno com 200 células e mantidas em germinador, durante 48 horas nas temperaturas de $20-30^{\circ} \mathrm{C}$ (testemunha), 30, 33 e $35^{\circ} \mathrm{C}$. Após esse período, todas as bandejas foram mantidas em ambiente de casa de vegetação para o desenvolvimento das mudas e foram realizadas as seguintes avaliações: emergência de plântulas: no 14ํㅜ dia após a semeadura (DAS), foi avaliada a porcentagem de plântulas normais emersas; índice de velocidade de emergência de plântulas (IVE): foram realizadas contagens diárias das plântulas normais emersas até o 14ํDAS, sendo o índice calculado pela equação proposta por MAGUIRE (1962); altura 
das mudas: após a emergência, a parte aérea de 20 plântulas por repetição foi medida a cada sete dias até o momento do transplantio das mudas; massa seca da parte aérea e das raízes: foi realizada aos 28DAS, com quatro repetições de 20 plântulas, as quais foram separadas em parte aérea e sistema radicular, secas em estufa a $68^{\circ} \mathrm{C}$ com circulação de ar, por 72 horas e posteriormente pesadas em balança analítica.

O delineamento experimental utilizado foi inteiramente casualizado em esquema fatorial $4 \mathrm{x} 4$ (lotes e tratamentos) em quatro repetições, sendo as médias comparadas entre si pelo teste de Tukey a 5\%.

\section{RESULTADOS E DISCUSSÃO}

Em relação à caracterização dos lotes de sementes de tomate, não foi observada diferença nos resultados de germinação (variando entre 96 a $86 \%$ para os lotes A e D, respectivamente), porém, avaliando os resultados de envelhecimento acelerado e condutividade elétrica, foi constatada diferença no vigor dos resultados. Pelo teste de envelhecimento acelerado, os lotes B e C foram classificados como sendo de menor vigor (64\%), uma vez que, após uma condição de estresse, tiveram menor porcentagem de germinação em relação aos demais (em torno de $75 \%$ ). Quanto ao teste de condutividade elétrica, a maior lixiviação de íons $\left(147,75 \mu \mathrm{S} \mathrm{cm}^{-1} \mathrm{~g}^{-1}\right)$ foi nas sementes do lote $\mathrm{D}$, após a embebição, devido a menor velocidade de reorganização das membranas celulares, caracterizando-o como o de menor vigor (VIEIRA et al., 2002); para as sementes dos outros lotes, a condutividade elétrica variou entre 113,00 a $124,00 \mu \mathrm{S} \mathrm{cm}^{-1} \mathrm{~g}^{-1}$.

A absorção de água pelas sementes de tomate foi mais acelerada nas primeiras 25 horas do processo de embebição para todos os tratamentos utilizados (Figura 1), caracterizando esse período como a primeira fase da germinação, pois nessa fase ocorre rápida absorção de água pelas sementes, até todo o conteúdo celular ser completamente hidratado. Dessa forma, é interessante caracterizar o processo de embebição das sementes, pois nesse momento o metabolismo das sementes é reativado, com aumento da atividade respiratória e liberação de energia para a germinação, ativação de enzimas e síntese de proteínas, a partir do RNAm armazenado ao final do processo de maturação, sendo que esse processo pode ser alterado em função da temperatura (MARCOS FILHO, 2005).

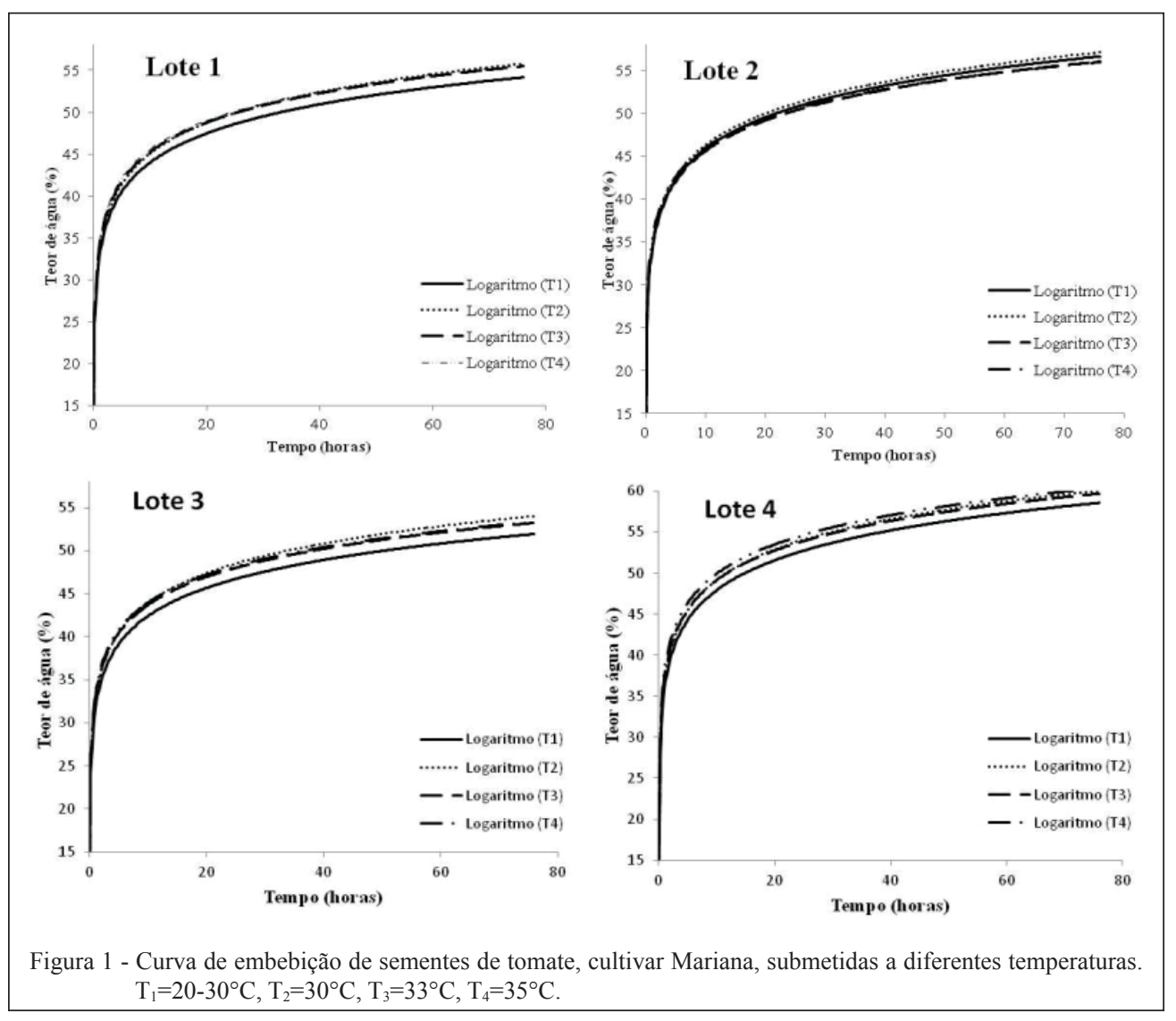

Ciência Rural, v.43, n.7, jul, 2013. 
Após esse período, foi verificada tendência de estabilização do teor de água das sementes, sendo essa fase conhecida como fase II da germinação, caracterizada por reduções drásticas na velocidade de hidratação e intensidade de respiração (MARCOS FILHO, 2005; NONOGAKI et al., 2010). Nessa etapa, foi verificado que as temperaturas de 30, 33 e $35^{\circ} \mathrm{C}$ proporcionaram maior absorção de água pelas sementes dos lotes 1,3 e 4, comparado ao tratamento controle $\left(20-30^{\circ} \mathrm{C}\right)$, e essa diferença permaneceu até a protrusão da raiz primária. Assim, fica claro que a variação na temperatura durante a Fase II alterou a velocidade de hidratação das sementes, ressaltando a necessidade de maior eficiência dos mecanismos de reparo das membranas e DNA, a fim de garantir uma boa germinação. Para isso, uma maior quantidade de enzimas, proteínas e substâncias protetoras são demandadas, requerendo, assim, uma maior quantidade de água, essencial para o bom desempenho desses compostos.
A partir da análise dos dados de plântulas obtidos por meio do software SVIS ${ }^{\circledR}$ (Tabela 1), as sementes dos lotes $\mathrm{A}$ e $\mathrm{C}$, submetidas às temperaturas de 35 e $33^{\circ} \mathrm{C}$, respectivamente, tiveram menor vigor em relação àquelas submetidas a $20-30^{\circ} \mathrm{C}$. Para os lotes $\mathrm{A}$ e $\mathrm{C}$, o índice de crescimento de plântulas foi menor quando as sementes foram submetidas às temperaturas de 33 e $35^{\circ} \mathrm{C}$ em relação às demais, enquanto para os lotes $\mathrm{B}$ e D somente a temperatura de $35^{\circ} \mathrm{C}$ reduziu o índice de crescimento, quando comparada às temperaturas de $20-30^{\circ} \mathrm{C}$.

O comprimento do hipocótilo foi reduzido em todos os lotes nas temperaturas de $30,33 \mathrm{e}$ $35^{\circ} \mathrm{C}$, enquanto o comprimento da raiz foi reduzido na temperatura de 30,33 e $35^{\circ} \mathrm{C}$, nas sementes dos lotes $\mathrm{B}$ e $\mathrm{C}$ em relação à temperatura de $20-30^{\circ} \mathrm{C}$; no lote $\mathrm{A}$, o comprimento da raiz foi reduzido nas temperaturas de 33 e $35^{\circ} \mathrm{C}$ e, no $\mathrm{D}$, apenas a $35^{\circ} \mathrm{C}$, de forma que o pior desempenho das plântulas foi nas temperaturas de 33 e $35^{\circ} \mathrm{C}$. Dentre os vários estádios de crescimento e desenvolvimento de plantas, a

Tabela 1 - Índice de vigor, de crescimento, comprimento de hipocótilo e raiz obtidos por meio da análise em SVIS ${ }^{\circledR}$, velocidade e porcentagem de emergência de plântulas de tamate oriundas de sementes de quatro lotes, cultivar Mariana, submetidas a diferentes temperaturas.

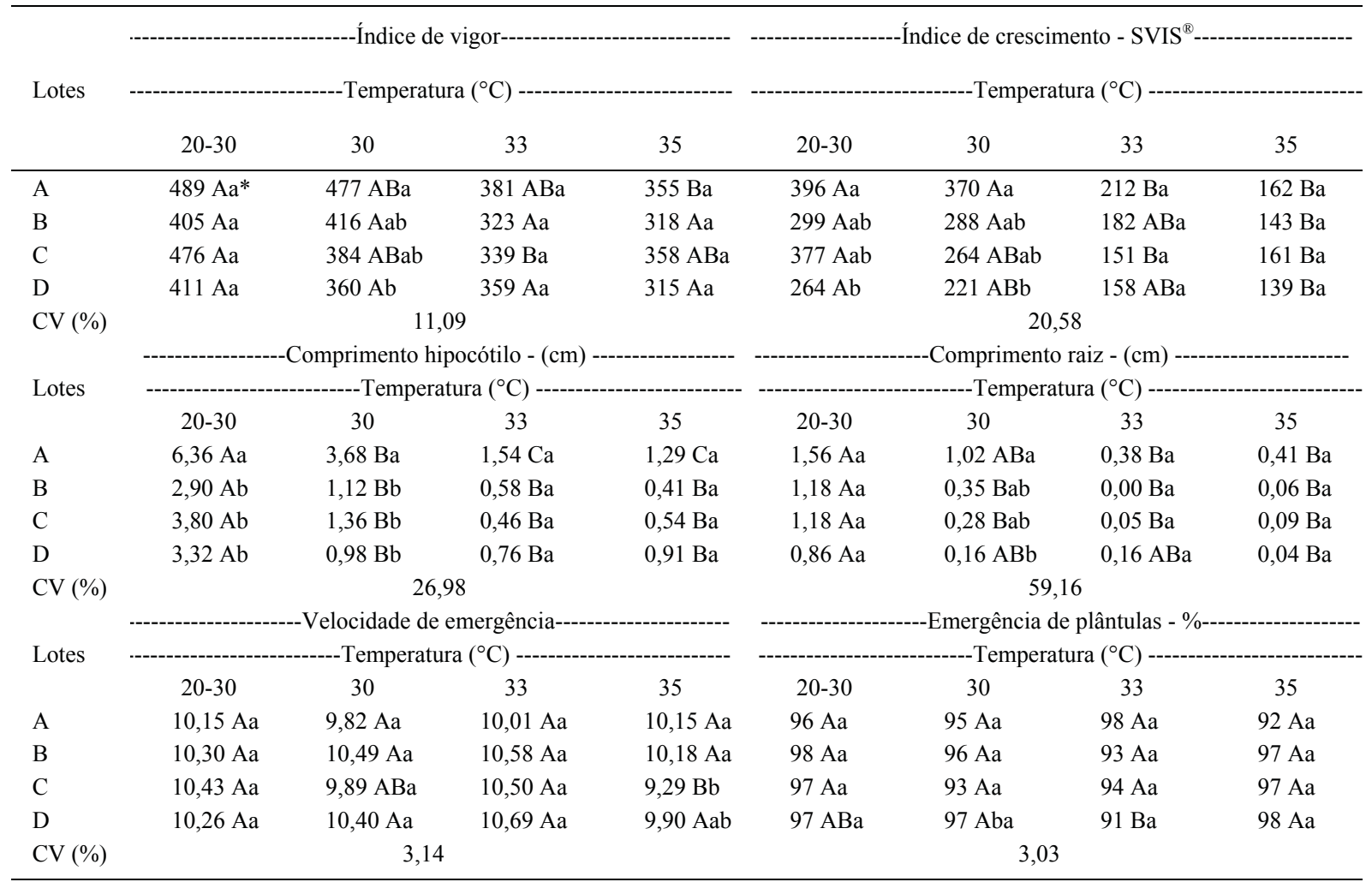

*Médias seguidas da mesma letra, maiúscula nas linhas e minúscula nas colunas, não diferem entre si pelo teste de Tukey a 5\% de probabilidade. 
germinação e o estabelecimento de plântulas são mais sensíveis a altas temperaturas (SPIERTZ et al., 2006).

$\mathrm{O}$ atraso no crescimento das plântulas, avaliado por meio do SVIS $^{\circledR}$, pode ser devido à termoinibição das sementes, provocada em altas temperaturas, durante as primeiras 48 horas da germinação. KEPCZYNSKA et al. (2006) verificaram que a $35^{\circ} \mathrm{C}$ a germinação de sementes de tomate não ocorreu, pois, nessa temperatura, houve correlação positiva entre a inibição da atividade da enzima endo- $\beta$-mananase e a germinação, uma vez que ela é responsável pela degradação da parede celular da região micropilar do endosperma, o que é fundamental para a protrusão da raiz primária (MO \& BEWLEY, 2003).

Por outro lado, o efeito inicial do estresse por alta temperatura pode ser devido à ruptura das membranas biológicas, levando à perda da sua função (XU et al., 2006; WAHID et al., 2007; NONOGAKI et al., 2010). Quando danificadas, organelas como mitocôndrias, vitais para a eficiência da respiração e metabolismo energético são reduzidas em número (NONOGAKI et al., 2010), interferindo diretamente na produção de ATP nas primeiras horas da embebição (ATTUCCI et al., 1991). A mitocôndria é uma das principais organelas suscetível a danos por diferentes estresses ambientais, como alta temperatura durante o crescimento e desenvolvimento de planta (LEVITT, 1980).
A velocidade de emergência de plântulas foi afetada pela temperatura de $35^{\circ} \mathrm{C}$ para o lote $\mathrm{C}$ e a porcentagem de emergência pela temperatura de $33^{\circ} \mathrm{C}$ para o lote $\mathrm{D}$ (Tabela 1 ), possivelmente essas temperaturas tenham afetado a velocidade de reorganização das membranas celulares, alterando assim o metabolismo das sementes e com isso reduzindo a velocidade de emergência de plântulas. Também é necessário destacar que os lotes de sementes comportaram-se de forma diferenciada quanto aos efeitos das altas temperaturas, pois possuem histórico distinto, além do que a velocidade de deterioração das sementes é diferente, sendo que até as partes componentes de uma mesma semente deterioram em velocidades distintas (MARCOS FILHO, 2005) e isso interfere no potencial fisiológico e na capacidade de resistir às condições adversas, impostas no momento da germinação e emergência.

A altura das plântulas de tomate aos sete DAS foi reduzida quando as sementes foram submetidas às temperaturas iniciais de germinação de 33 e $35^{\circ} \mathrm{C}$ em relação àquelas submetidas a $30^{\circ} \mathrm{C}$ para o lote A (Tabela 2), enquanto, para o lote B, esse fato ocorreu em todas as temperaturas acima da ideal; o mesmo caso aconteceu aos 14DAS para todos os lotes e aos 21DAS para os lotes B e D. Por esses resultados, percebe-se que alguns lotes são mais sensíveis às altas temperaturas na fase inicial de germinação, isso porque eles possuem potencial

Tabela 2 - Altura de plântulas de tomate (cm), cultivar 'Mariana' aos 7, 14, 21 e 28 dias após a semeadura (DAS) oriundas de sementes de quatro lotes submetidas a diferentes temperaturas.

\begin{tabular}{|c|c|c|c|c|c|c|c|c|}
\hline \multirow[t]{2}{*}{ Lotes } & \multicolumn{4}{|c|}{---------------------Temperatura $\left({ }^{\circ} \mathrm{C}\right)$--------------------- } & \multicolumn{4}{|c|}{----Temperatura $\left({ }^{\circ} \mathrm{C}\right)$----------------------- } \\
\hline & $20-30$ & 30 & 33 & 35 & $20-30$ & 30 & 33 & 35 \\
\hline A & $2,8 \mathrm{ABa}^{*}$ & $2,9 \mathrm{Aa}$ & $2,0 \mathrm{Ca}$ & $2,3 \mathrm{BCa}$ & $5,0 \mathrm{Ab}$ & $3,8 \mathrm{Bab}$ & $3,1 \mathrm{Bb}$ & $3,4 \mathrm{Ba}$ \\
\hline B & $2,8 \mathrm{Aa}$ & $2,2 \mathrm{Bb}$ & $2,1 \mathrm{Ba}$ & $2,2 \mathrm{Ba}$ & $5,4 \mathrm{Ab}$ & $3,5 \mathrm{Bab}$ & $3,9 \mathrm{Ba}$ & $3,7 \mathrm{Ba}$ \\
\hline $\mathrm{C}$ & 2,5 Aab & $2,5 \mathrm{Ab}$ & $2,4 \mathrm{Aa}$ & $2,3 \mathrm{Aa}$ & $4,7 \mathrm{Ab}$ & $3,4 \mathrm{Cb}$ & $2,9 \mathrm{Cb}$ & $4,0 \mathrm{Ba}$ \\
\hline $\mathrm{D}$ & $2,4 \mathrm{Ab}$ & $2,3 \mathrm{Ab}$ & 2,0 Aa & $2,1 \mathrm{Aa}$ & $6,1 \mathrm{Aa}$ & $4,0 \mathrm{Ba}$ & $3,9 \mathrm{Ba}$ & $4,1 \mathrm{Ba}$ \\
\hline CV $(\%)$ & \multicolumn{4}{|c|}{6,29} & \multicolumn{4}{|c|}{4,70} \\
\hline \multirow[t]{2}{*}{ Lotes } & -----------. & ----------21D & $\left.{ }^{\circ} \mathrm{C}\right)$ - & ------------- & - & ---Tempe & $\left({ }^{\circ} \mathrm{C}\right)$ & -------. \\
\hline & $20-30$ & 30 & 33 & 35 & $20-30$ & 30 & 33 & 35 \\
\hline A & $11,5 \mathrm{Ab}$ & $10,2 \mathrm{BCab}$ & $9,1 \mathrm{Ca}$ & $10,4 \mathrm{ABa}$ & $23,3 \mathrm{Aa}$ & $22,8 \mathrm{Aa}$ & 21,9 Aa & $21,7 \mathrm{Aa}$ \\
\hline B & 11,9 Aab & $8,7 \mathrm{Cb}$ & $10,0 \mathrm{BCa}$ & $10,6 \mathrm{Ba}$ & $23,3 \mathrm{ABa}$ & $21,1 \mathrm{Aa}$ & $22,3 \mathrm{ABa}$ & $23,7 \mathrm{Ba}$ \\
\hline $\mathrm{C}$ & $11,4 \mathrm{Ab}$ & 9,5 Bab & $8,9 \mathrm{Ba}$ & $10,8 \mathrm{Aa}$ & $22,5 \mathrm{Aa}$ & $22,0 \mathrm{Aa}$ & $22,4 \mathrm{Aa}$ & $23,3 \mathrm{Aa}$ \\
\hline $\mathrm{D}$ & $13,2 \mathrm{Aa}$ & $10,3 \mathrm{Ba}$ & $9,8 \mathrm{Ba}$ & $10,6 \mathrm{Ba}$ & $23,0 \mathrm{Aa}$ & $22,2 \mathrm{Aa}$ & $21,0 \mathrm{Aa}$ & $23,0 \mathrm{Aa}$ \\
\hline CV (\%) & \multicolumn{4}{|c|}{4,71} & \multicolumn{4}{|c|}{4,00} \\
\hline
\end{tabular}

*Médias seguidas da mesma letra, maiúscula nas linhas e minúscula nas colunas, não diferem entre si pelo teste de Tukey a $5 \%$ de probabilidade. 
fisiológico diferente e capacidades distintas de tolerância, enquanto aos 28DAS não houve diferença significativa entre os tratamentos para os lotes A, C e D. Provavelmente, esse fato ocorreu porque nesse estádio as mudas estavam desenvolvidas e possuíam capacidade de suportar as condições adversas.

A massa seca da parte aérea e das raízes das mudas não foi influenciada pela temperatura, cujos valores variaram entre 2,27 e $2,72 \mathrm{mg}$ e entre 0,49 e $0,69 \mathrm{mg}$, respectivamente (dados não apresentados), possivelmente porque esses resultados mostram que as temperaturas elevadas na fase inicial de germinação não causaram efeito negativo para as mudas de tomate no final do ciclo, pois aos 28DAS houve o efeito de compensação, não afetando a massa seca da parte aérea e das raízes.

De acordo com os resultados, não foi verificada interferência da temperatura no desempenho das mudas, apesar do efeito negativo no crescimento inicial verificado por meio do SVIS ${ }^{\circledR}$. Além disso, o crescimento das plântulas foi compensado durante a emergência até o $14^{\circ}$ dia DAS.

\section{CONCLUSÃO}

Nas condições em que o trabalho foi realizado, os efeitos da temperatura na fase inicial da germinação de sementes de tomate não se manifestam no desenvolvimento final das mudas.

\section{REFERÊNCIAS}

ATTUCCI, S. et al. Oxidative phosphorylation by mitochondria extracted from dry sunflower seeds. Plant Physiology, v.95, n.1, p.390-398, 1991. Disponível em: <http://www.plantphysiol. org/content/95/2/390.full.pdf + html? sid $=$ d1 f11971-d1b3-48dda475-ac93c404789d>. Acesso em: 17 set. 2011. doi: 10.1104/ pp.95.2.390.

ANDRIOLO, J.L. Olericultura geral: princípios e técnicas. Santa Maria: UFSM, 2002. 158p.

BRASIL. Ministério da Agricultura, Pecuária e Abastecimento. Regras para análise de sementes. Secretaria de Defesa Agropecuária. Brasília: MAPA/ACS, 2009. 395p.

CARVALHO, N.M.; NAKAGAWA, J. Sementes: ciência, tecnologia e produção. Jaboticabal: FUNEP. 2000. 588p.

HOFFMASTER, A.L. et al. An automated system for vigour testing three-day-old soybean seedlings. Seed Science and Technology, v.31, n.3, p.701-713, 2003. Disponível em: <http://www. ingentaconnect.com/content/ista/sst/2003/00000031/00000003/ art00019>. Acesso em: 10 set. 2011.

ISTA (INTERNATIONAL SEED TESTING ASSOCIATION). Handbook of vigour test methods. 3.ed. Zürich, 1995. 117p.
JIANHUA, Z.; McDONALD, M.B. The saturated salt accelerated aging test for small-seeded crops. Seed Science and Technology, v. 25, n.1, p.123-131, 1996.

KEPCZYNSKA, E. et al. Hormonal regulation of tomato seed germination at a supraoptimal temperature. Acta Physiologiae Plantarum, v.28, n.3, p.225-231, 2006. Disponível em: <https:// springerlink3.metapress.com/content/jw52m147470p5368/ resource>. Acesso em: 08 jun. 2010. doi: 10.1007/BF02706534.

EVITT, J. Responses of plants to environmental stresses. New York: Academic, 1980. 497p.

MAGUIRE, J.D. Speed of germination-aid in selection and evaluation for seedling emergence and vigor. Crop Science, v.2, n.2, p.176-177, 1962. Disponível em: <https:/www.crops.org/ publications/cs/pdfs/2/2/CS0020020176>. Acesso em: 25 ago. 2010. doi: 10.2135/cropsci1962.0011183X000200020033x.

MARCOS FILHO, J. Fisiologia de sementes de plantas cultivadas. Piracicaba: FEALQ, 2005. 495p.

MO, B.; BEWLEY, J.D. The relationship between b-mannosidase and endo-b-mannanase activities in tomato seeds during and following germination: a comparison of seed populations and individual seeds. Journal of Experimental Botany, v.54, n.392, p.2503-2510, 2003. Disponível em: <http://jxb.oxfordjournals. org/content/54/392/2503.full.pdf+html>. Acesso em: 05 jul. 2010. doi: $10.1093 / \mathrm{jxb} / \mathrm{erg} 274$.

NASCIMENTO, W.M.; CANTLIFFE, D.J. Germinação de sementes de alface sob altas temperaturas. Horticultura Brasileira, v.20, n.1, p.103-106, 2002. Disponível em: <http:// www.scielo.br/pdf/hb/v20n1/14427.pdf $>$. Acesso em: 17 set. 2011. doi: $10.1590 / \mathrm{S} 0102-05362002000100020$.

NONOGAKI, H. Seed germination and reserve mobilization. In: Encyclopedia of life sciences. Chichester: John Wiley \& Sons, 2008. Disponível em: <http://www.els.net>. Acesso em: 17 set. 2011. doi: 10.1002/9780470015902.a0002047.pub2.

NONOGAKI, H. et al. Germination still a mystery. Plant Science, v.179, n.1, p.574-581, 2010. Disponível em: $<$ http:// www.sciencedirect.com/science/article/pii/S0168945210000403>. Acesso em: 15 ago. 2010. doi: 10.1016/j.plantsci.2010.02.010.

SILVA, V.N.; CICERO, S.M. Avaliação do potencial fisiológico de sementes de tomate por meio de análise computadorizada de plântulas. In: CONGRESSO BRASILEIRO DE SEMENTES, 17., 2011, Natal, RN. Anais... Informativo ABRATES, v.21, n.2, ago. 2011.

SOZZI, G.O. et al. Effect of a high-temperature stress on endo+mannanase and a- and B-galactosidase activities during tomato fruit ripening. Postharvest Biology and Technology, v.9, n.1, p.49-63, 1996. Disponível em: <http://www.sciencedirect. com/science/article/pii/0925521496000142>. Acesso em: 02 jul. 2011. doi: 10.1016/0925-5214(96)00014-2.

SPIERTZ, J.H.J. et al. Heat stress in wheat Triticum aestivum (L.): effects on grain growth and quality traits. European Journal of Agronomy, v.25, n.1, p.89-95, 2006. Disponível em: <http:// www.sciencedirect.com/science/article/pii/S1161030106000402>. Acesso em: 05 jul. 2010. doi: 10.1016/j.eja.2006.04.012.

STEINER, F. et at. Germinação de sementes de rabanete sob temperaturas adversas. Revista Brasileira de Ciências Agrárias, 
v.4, n.4, p.430-434, 2009. Disponível em: <http://agraria.pro.br/ sistema/index.php?journal $=$ agraria \&page $=$ article $\&$ op $=$ viewFile \&path $\% 5 \mathrm{~B} \% 5 \mathrm{D}=606 \&$ path $\% 5 \mathrm{~B} \% 5 \mathrm{D}=609>$. Acesso em: 11 set. 2011. doi: 10.5039/agraria.v4i4a10.

VIEIRA, R.O. et al. Condutividade elétrica e teor de água inicial de sementes de soja. Pesquisa Agropecuária Brasileira, v.37, n.9, p.1333-1338, 2002. Disponível em: <http://webnotes.sct. embrapa.br/pab/pab.nsf/FrAnual $>$. Acesso em: 1 set. 2011. doi: 10.1590/S0100-204X2002000900018.

WAHID, A. et al. Heat tolerance in plants: an overview. Environmental and Experimental Botany, v.61, n.1, p.199-
223, 2007. Disponível em: <http://www.scopus.com/record/ display.url?eid=2-s2.034848843547\&origin=inward\&txGid $=\mathrm{BHj}$ D7ICirZO-Cmac_iUP5iQ\%3a2>. Acesso em: 05 ago. 2011. doi: 10.1016/j.envexpbot.2007.05.011.

$\mathrm{XU}, \mathrm{S}$. et al. Effects of heat acclimation pretreatment on changes of membrane lipid peroxidation, antioxidant metabolites, and ultrastructure of chloroplasts in two cool-season turfgrass species under heat stress. Environmental and Experimental Botany, v.56, n.3, p.274-285, 2006. Disponível em: <http://www. sciencedirect.com/science/article/pii/S0098847205000523>. Acesso em: 25 jun. 2010. doi: 10.1016/j.envexpbot.2005.03.002.

Ciência Rural, v.43, n.7, jul, 2013. 